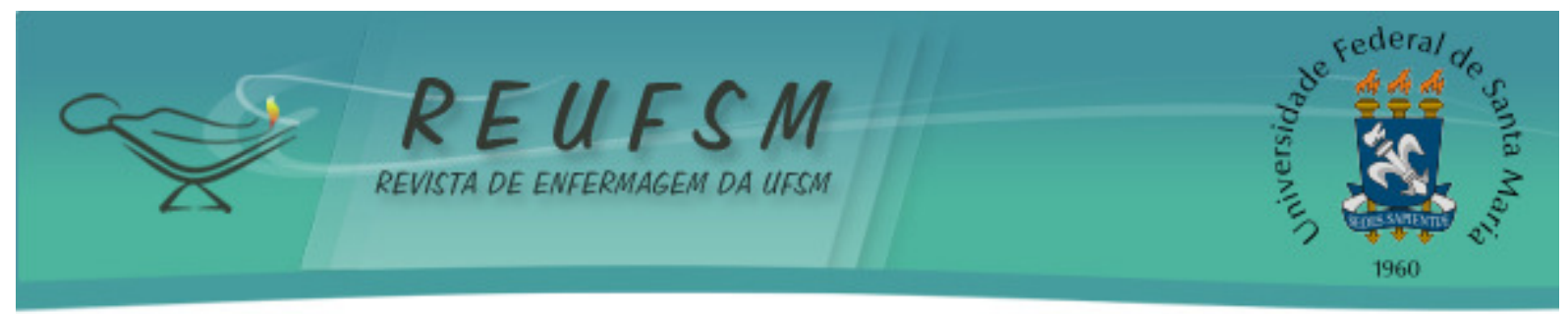

ARTIGO ORIGINAL

\title{
DISCIPLINA NA MODALIDADE SEMIPRESENCIAL EM ENFERMAGEM: AVALIAÇÃO DE QUALIDADE SEGUNDO SISTEMA DE INDICADORES
}

\author{
HYBRID COURSE IN NURSING: ASSESSMENT OF QUALITY ACCORDING TO THE \\ INDICATORS SYSTEM
}

\section{ASIGNATURA EN MODO SEMIPRESENCIAL EN ENFERMERÍA: EVALUACIÓN DE LA CALIDAD SEGÚN EL SISTEMA DE INDICADORES}

Simone Shirasaki Orosco ${ }^{1}$ Mariane Franzini Puglia ${ }^{2}$

Doi: $10.5902 / 2179769212903$

Karen Lucia Gama Duarte ${ }^{3}$

RESUMO: Objetivo: avaliar duas disciplinas na modalidade semipresencial em um curso de graduação em enfermagem. Método: trata-se de uma pesquisa descritiva, transversal, quantitativa. Aplicou-se um instrumento baseado em indicadores acerca de entradas, processo e resultados a 43 alunos do terceiro e sexto períodos que participaram de disciplinas em modalidade semipresencial. Os dados foram apresentados em tabelas com frequências simples e percentuais. Resultados: os indicadores de entradas e resultados foram avaliados como bons. Já os indicadores de processo como suporte técnico prestado, nível de flexibilização da sua aprendizagem em relação ao tempo e ao espaço e a avaliação da aprendizagem desenvolvida na disciplina foram avaliados como regulares. Considerações Finais: os resultados demonstram a necessidade de reorganização das disciplinas. Sugere-se o incentivo e capacitação dos docentes para o uso das novas tecnologias, visto que organiza e inova o processo de ensino-aprendizagem, além do desenvolvimento de pesquisas na área.

Descritores: Educação em enfermagem; Educação a distância; Avaliação.

ABSTRACT: Aim: to evaluate two hybrid courses in an undergraduate program in nursing. Method: this is a descriptive, transversal, and quantitative research. An instrument based on indicators of inputs, process, and results was applied to 43 undergraduate students of the third and sixth terms who attended hybrid courses. The data were presented in tables with simple frequencies and percentages. Results: the indicators of inputs and results were assessed as good. Yet, the indicators of process, such as technical support provided, level of learning flexibility with respect to time and space, and the assessment of learning developed in the course, were assessed as poor. Final considerations: the results showed the need to reorganize the courses. It is suggested that there is incentive and professional training so that the professors are able to use the new technologies, since that organizes and innovates the teaching-learning process, as well as the development of research in the field.

Descriptors: Education in nursing; Distance education; Assessment.

\footnotetext{
1 Enfermeira, Mestre em Educação, docente dos cursos de graduação em Enfermagem e Medicina da Universidade do Oeste Paulista (UNOESTE), Presidente Prudente, São Paulo, Brasil. E-mail: simone.orosco@hotmail.com

${ }^{2}$ Enfermeira, Graduada em Enfermagem pela Universidade do Oeste Paulista (UNOESTE), Presidente Prudente, São Paulo, Brasil. E-mail: marianefranzini@hotmail.com

${ }^{3}$ Enfermeira, Graduada em Enfermagem pela Universidade do Oeste Paulista (UNOESTE), Presidente Prudente, São Paulo, Brasil. E-mail: karen.gama.duarte@gmail.com
} 


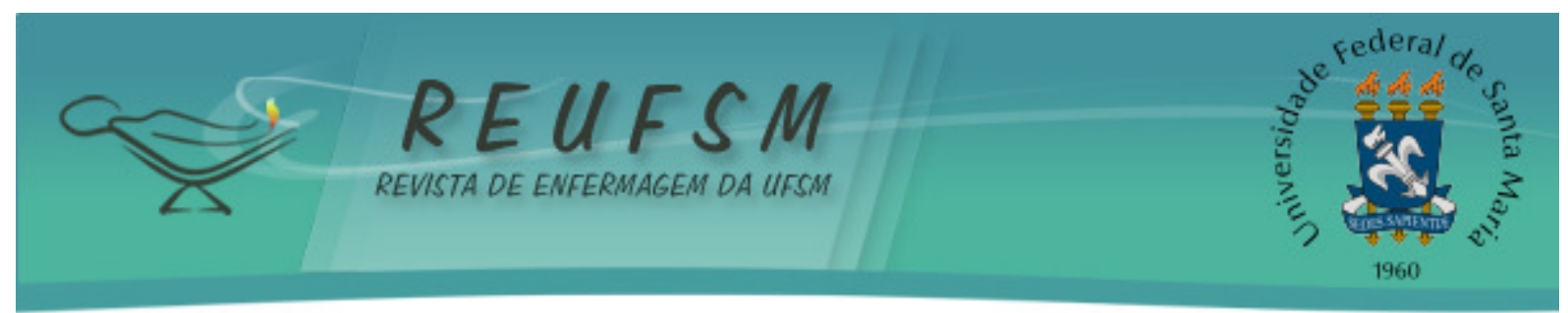

RESUMEN: Objetivo: evaluar dos asignaturas de modo semipresencial en un curso de grado de enfermería. Método: investigación descriptiva, transversal y cuantitativa. Fue aplicado un instrumento basado en indicadores de entradas, proceso y resultados a 43 alumnos de tercer y sexto semestre. Los datos fueron presentados en tablas con frecuencias simples y porcentajes. Resultados: los indicadores de entradas y resultados fueron evaluados como buenos. Los indicadores de proceso como apoyo técnico ofrecido, nivel de flexibilidad del aprendizaje en relación al tiempo y al espacio y la evaluación del aprendizaje desarrollado en la asignatura fueron evaluados como regulares. Consideraciones finales: los resultados demuestran la necesidad de reorganización de las asignaturas. Se sugiere incentivar la formación de los docentes en el uso de las nuevas tecnologías, dado que éstas organizan e innovan el proceso de enseñanza-aprendizaje, además del desarrollo de investigaciones en el área.

Descriptores: Educación en enfermería; Educación a distancia; Evaluación.

\section{INTRODUÇÃO}

As novas Tecnologias da Informação e Comunicação (TICs) têm modificado o ensino e as relações entre o indivíduo, o trabalho e a sociedade, quando tais inovações tecnológicas constituem importantes recursos para concretização da globalização. ${ }^{1}$

As TICs possibilitam a criação coletiva, a aprendizagem cooperativa e de colaboração em rede, além de propiciar o questionamento do processo de trabalho em instituições empresariais e escolares. ${ }^{2}$

O ensino sofre alterações com as mudanças ocorridas na sociedade e faz com que professores e alunos percebam que as aulas convencionais já estão ultrapassadas. As tecnologias estão cada vez mais em evidência e os investimentos visam alunos conectados à internet. ${ }^{3}$

A tecnologia envolve não só os equipamentos na produção, mas também um certo saber tecnológico e um modo de fazer que dão sentido ao que será ou não a "razão instrumental" do equipamento. ${ }^{4}$ Dessa forma, o desenvolvimento de tecnologias aplicadas ao ensino compreende tecnologia como um conjunto de conhecimentos, especialmente princípios científicos, aplicados ao processo de aprendizagem. ${ }^{5}$

Aliada a esse processo e atualização dos profissionais, a internet permite que barreiras físicas sejam superadas, possibilita o desenvolvimento de cursos de Educação a Distância (EAD) com alto nível de interatividade, favorece o desenvolvimento de atividades tanto síncronas quanto assíncronas e ultrapassa outras formas de EAD como o rádio e a televisão. ${ }^{6}$

Plataformas para EAD ou Ambientes Virtuais de Ensino e Aprendizagem (AVEA), configuram-se em espaços importantes para reunir grupos e compartilhar conhecimentos. ${ }^{7}$

A EAD é uma modalidade de ensino que pode ser utilizada no âmbito presencial, híbrido ou totalmente à distância. Assim, questiona-se o papel do professor neste contexto, pois ele não seria um mero transmissor de informação, mas um mediador que organiza, dinamiza e orienta a construção de conhecimento pelo aluno, de forma a favorecer um posicionamento critico e ativo frente ao mundo de informações disponíveis atualmente. ${ }^{8}$

Ao mesmo tempo, o professor desenvolve a competência da gestão para organizar as atividades que proporcionam aprendizagem pela internet, para manter a motivação, fornecer novas experiências para a classe e enriquecer o repertório do grupo. ${ }^{9}$

Diante desse contexto, as Diretrizes Curriculares Nacionais do Curso de Graduação em Enfermagem dizem que ao enfermeiro compete o domínio de tecnologias de comunicação e informação. Assim, o uso de novas tecnologias no ensino de enfermagem favorece processos de ensino-aprendizagem mais flexíveis, dinâmicos, criativos, interativos, e estimula a participação ativa e coletiva do aluno na construção do conhecimento. ${ }^{8}$ 


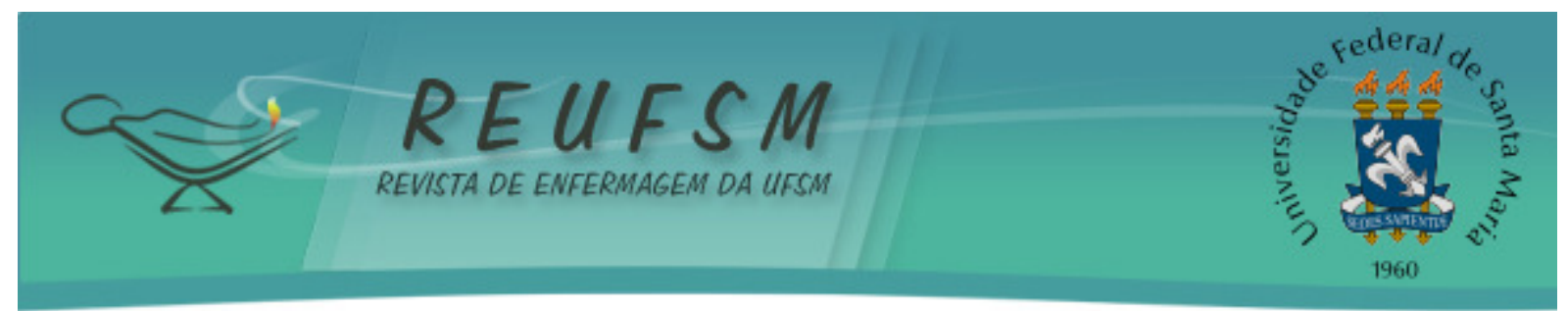

Existem leis e portarias que regulamentam a educação à distância nas instituições de ensino. Porém, mesmo com todo aparato legal, a movimentação em torno da EAD ainda é muito pequena, provavelmente pelo desconhecimento de sua potencialidade ou pela falta de estudos que comprovem tal eficácia em comparação com o ensino tradicional e presencial. Os cursos de EAD são vistos, até o momento, como iniciativas experimentais na área de saúde, principalmente na área de enfermagem., ${ }^{6,10}$

Nesse sentido, destaca-se a modalidade semipresencial como proposta que reflete uma tendência educacional nas instituições de educação superior do país e aposta na ampliação das possibilidades de interação no fazer pedagógico. ${ }^{11} \mathrm{O}$ aperfeiçoamento desta modalidade nos cursos de graduação está vinculado à constante reflexão acerca dessa iniciativa com participação da própria instituição; dos docentes e dos discentes. Isso requer, portanto, pesquisas e avaliações acerca da qualidade da modalidade como um todo. ${ }^{12}$

Diante disso, no segundo semestre de 2012 iniciaram duas disciplinas na modalidade semipresencial no segundo e quinto períodos de um curso de graduação em enfermagem. Um questionamento surgiu durante a elaboração do material, organização de atividades em ambiente virtual de aprendizagem e condução da disciplina: como os alunos do curso de graduação em enfermagem avaliam a qualidade das disciplinas na modalidade semipresencial?

O desenvolvimento de pesquisas, publicações e discussões sobre a EAD tem sido ínfimo na realidade brasileira. Além disso, a abordagem sobre o ensino de Enfermagem e o uso das TICs ainda é incipiente. ${ }^{10}$

A avaliação de disciplinas semipresenciais deve ser desenvolvida com a participação de todos os sujeitos interessados (instituição, docentes e discentes), por meio de instrumentos constituídos por indicadores sistêmicos que expressam as especificidades e particularidades dessa modalidade. ${ }^{12}$

Contudo, as avaliações de EAD desenvolvidas até o momento não destacam todos os aspectos do desenvolvimento da modalidade, isto é, indicadores de entradas (insumos), processo e resultados (produtos educativos). ${ }^{12}$

Os indicadores de entradas referem-se aos recursos, tanto financeiros como humanos e tecnológicos, que se destinam à educação. Os indicadores de processo referemse ao contexto pedagógico e organizacional e os indicadores de resultados às características relativas aos propósitos intermediários e últimos da educação. ${ }^{13}$

Diante do exposto e da relevância da temática para o ensino em enfermagem, o presente estudo teve como objetivo avaliar duas disciplinas na modalidade semipresencial em um curso de graduação em enfermagem, ao considerar os indicadores de entradas, processo e resultados.

\section{MÉTODO}

Trata-se de um estudo descritivo, transversal, quantitativo. A pesquisa foi realizada em uma universidade privada no interior paulista. Como critérios de inclusão, utilizaram-se: alunos que participaram de duas disciplinas na modalidade semipresencial no curso de graduação em enfermagem no segundo semestre do ano de 2012. Excluíram-se os alunos em licença de qualquer natureza ou que não estavam presentes no dia da coleta de dados. Neste dia, havia 30 alunos matriculados no terceiro período e 18 alunos no sexto período. Desses, todos atenderam aos critérios de elegibilidade, porém 2,08\% não aceitaram participar da pesquisa e $8,33 \%$ não estavam presentes na sala de aula. Logo, obteve-se um total 43 alunos. Ao iniciar a pesquisa em 2013 os alunos não tinham mais aula com os professores das referidas disciplinas. 


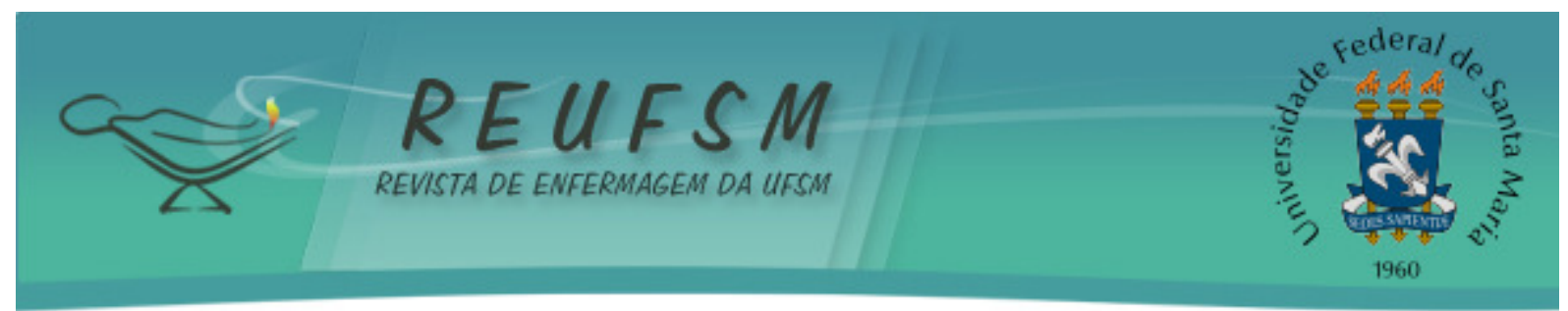

Os aspectos éticos da pesquisa foram conduzidos de acordo com a Resolução 466/2012 do Conselho Nacional de Saúde, após aprovação do Comitê de Ética em Pesquisa (CEP) da Coordenadoria Central de Pesquisa (CCPq), com parecer favorável, sob protocolo №.1528.

A coleta de dados foi realizada na segunda quinzena de fevereiro de 2013 , com uso de instrumento para avaliação de duas disciplinas semipresenciais que foi desenvolvido como proposta para verificar a qualidade segundo sistemas de indicadores por Bertolin e De Marchi. ${ }^{12}$

$\mathrm{O}$ instrumento é baseado em indicadores acerca das entradas, processo e resultados educativos, ou das relações entre eles. Para que a avaliação de uma disciplina semipresencial seja completa e confiável é importante a participação de todos os sujeitos interessados na qualidade e no bom desempenho do processo de aprendizagem, ou seja, alunos, professores e pessoal de suporte. Assim, o instrumento aborda pontos de avaliação específicos para os diferentes sujeitos envolvidos no processo. ${ }^{12}$

Para fins deste estudo, foi utilizado apenas o instrumento para os alunos, uma vez que um dos professores é o próprio pesquisador e o instrumento destinado ao pessoal de suporte apresenta questões relacionadas ao indicador de processo que dependem da participação direta no processo de educação, que não ocorreu em razão desta pesquisa ter sido realizada após o final da oferta das disciplinas.

0 instrumento foi distribuído aos sujeitos que aceitaram participar da pesquisa e assinaram o Termo de Consentimento Livre e Esclarecido. Esses responderam individualmente no final da aula, após autorização prévia do professor e o devolveram imediatamente sem qualquer forma de identificação.

Os dados foram organizados e analisados por meio da construção de planilhas com uso do aplicativo Microsoft Excel $2010^{\circledR}$ e consequente construção de tabelas para estabelecimento de frequências simples e percentuais. A análise descritiva dos dados foi realizada de acordo com as categorias identificadas no instrumento (indicadores de entradas, processo e resultados).

\section{RESULTADOS E DISCUSSÃO}

A amostra deste estudo caracterizou-se por participantes na faixa etária entre 18 e 20 anos $(46,5 \%)$, com predomínio do sexo feminino $(83,7 \%)$ e que já frequentaram algum curso ou disciplina online $(95,3 \%)$.

A avaliação dos alunos dos terceiro e sexto períodos sobre disciplinas semipresenciais foi categorizada segundo os indicadores de entradas, processo e resultados, os quais se encontram descritos a seguir.

\section{Indicadores de entradas}

Os dados sobre os indicadores de entrada que consideram os aspectos relativos aos gastos com educação, investimento com tecnologia de informações e quantidade e formação dos docentes são apresentados na tabela 1 a seguir. 


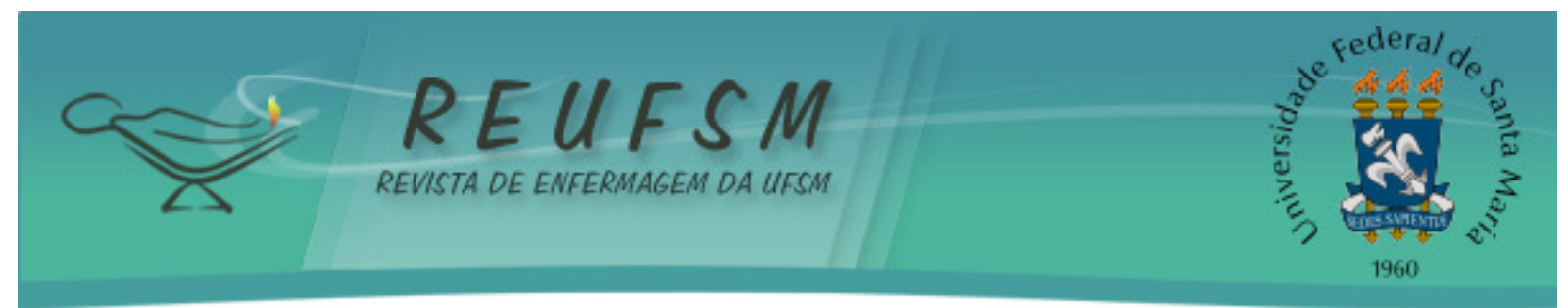

Tabela 1 - Porcentagem de respostas dos participantes da pesquisa, segundo indicadores de entrada. Presidente Prudente/SP, 2013 ( $n=43)$.

Entrada

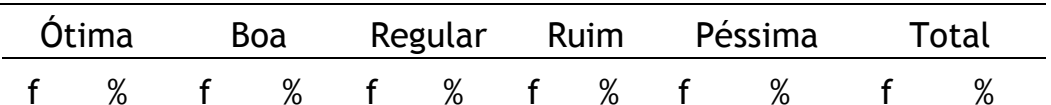

EA1- A infraestrutura de EAD (ambiente/software de aprendizagem, recursos de vídeoconferência etc.) disponibilizada pela instituição para a disciplina pode ser avaliada como?

EA2- As habilidades e competências do professor e dos tutores para desenvolvimento da disciplina semipresencial podem ser avaliadas como?

EA3- As sua habilidades de uso de computador antes do início da disciplina podem ser avaliadas como?

EA4- O planejamento (plano de ensino, carga horária EAD, material didático, bibliografia, mídias etc.) realizado pelo(a) professor(a) para a disciplina pode ser avaliado como?

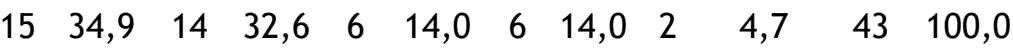

$\begin{array}{llllllllllll}15 & 34,9 & 20 & 46,5 & 5 & 11,6 & 1 & 2,3 & 2 & 4,7 & 43 & 100,0\end{array}$

A infraestrutura de EAD disponibilizada pela instituição para as disciplinas foi avaliada como boa por $60,5 \%$ dos participantes da pesquisa. Essa realidade não é a mesma de muitas universidades no país, visto que um estudo aponta que muitas universidades não podem fazer uso da informática como recurso tecnológico na formação em saúde, pois não dispõem do equipamento necessário, sobretudo, em função do alto custo. ${ }^{7}$

Apesar de poucos cursos disponibilizarem boa infraestrutura de EAD, essa se torna cada vez mais necessária para uma educação de qualidade. Os novos espaços de atuação do professor com as tecnologias devem ter uma infraestrutura que possibilite mudanças em sua postura, para ajudar de um lado, na organização das informações, enquanto, do outro lado, no incentivo a aprendizagem, de forma a provocar no aluno o estímulo a mudanças, a não permanecer acomodado. ${ }^{9}$

Em uma pesquisa sobre avaliação de um curso de educação à distância por alunos de enfermagem, o limite de acesso ao computador foi apontado como um importante obstáculo para a continuidade do curso, além das tutoras sentirem dificuldades em lidar com as constantes manutenções do ambiente virtual de aprendizagem. ${ }^{14}$

Quanto às habilidades e competências do professor e dos tutores para desenvolvimento da disciplina semipresencial, 34,9\% dos participantes avaliaram como ótimas. Nesse sentido, estudo demonstra que professor e tutor também apresentaram habilidades e competências para o desenvolvimento de curso a distância sobre cardioversão e desfibrilação segundo os enfermeiros participantes do mesmo. ${ }^{4}$

Isso demonstra que educar com qualidade implica ao professor ter acesso e competência para organizar e gerenciar as atividades didáticas em sala de aula, mas também atividades a distância, visitas técnicas e orientação de projetos. ${ }^{8}$ Ainda, é preciso que o professor seja um mediador entre o aluno e a aprendizagem, de forma a promover o 


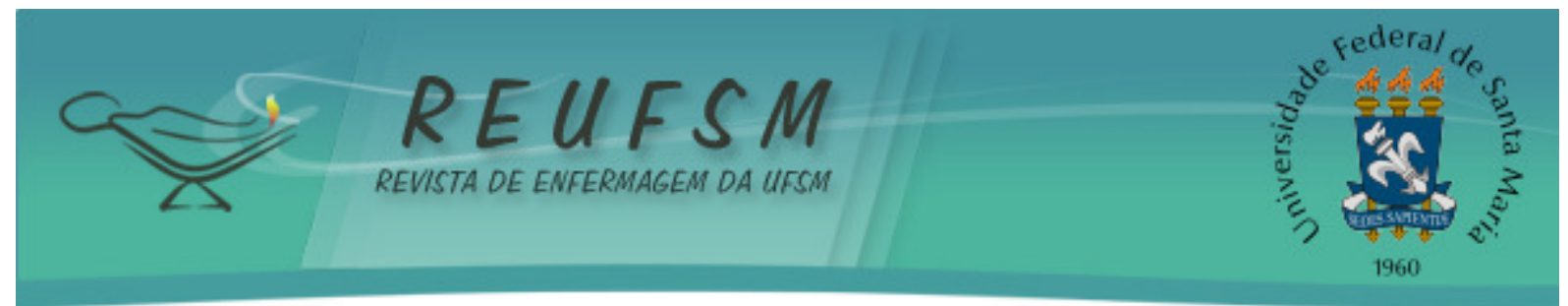

pensamento sobre seus projetos, possibilitar o compartilhamento de problemas sem apontar soluções e ajudar o aprendiz a entender, analisar, testar e corrigir erros. ${ }^{3}$

Aponta-se ainda que as instituições de ensino além de dinamizar os conteúdos e métodos, devem investir na capacitação dos professores para fazer uso das ferramentas da informática. $^{7}$

Observou-se que $46,5 \%$ dos participantes consideram boas suas habilidades no uso de computador antes do início da disciplina. Isso vai ao encontro do estudo que avaliou a habilidade dos alunos em relação aos recursos da internet e aponta que a maior parte dos estudantes possui maior habilidade em manusear o e-mail. Eles consideram suas habilidades de navegação na internet ótimas e regulares e as menores habilidades constatadas foram na realização de downloads de programas e uso de fóruns e chats. ${ }^{2}$

0 planejamento realizado pelos professores para as disciplinas foi avaliado como bom por $46,5 \%$ dos sujeitos. Nesse estudo e no estudo com enfermeiros de um curso a distância, consideram-se mais positivos os aspectos relacionados ao planejamento como o uso de imagem adequado; o conteúdo e a dinâmica contribuíram para o aprendizado; compreenderam facilmente a linguagem adotada e declararam que houve flexibilidade quanto aos horários. ${ }^{6}$

\section{Indicadores de processo}

Os indicadores de processo fazem alusão ao "contexto pedagógico e organizacional ou características primárias, relativas à participação direta no processo de educação, e secundárias, relativas ao apoio à organização das características primárias". ${ }^{12: 135}$ Os dados da pesquisa relacionados a este indicador encontram-se descritos na tabela 2 a seguir. 


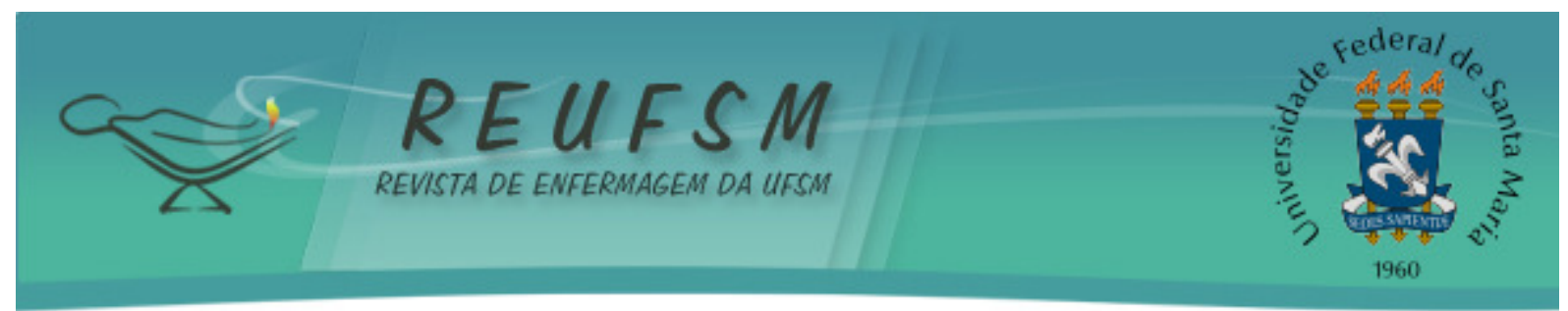

Tabela 2 - Porcentagem de respostas dos participantes da pesquisa, segundo indicadores de processo. Presidente Prudente/SP, $2013(\mathrm{n}=43)$.

Processo

PA1- A interação dialógica desenvolvida entre professortutor-aluno durante a disciplina pode ser avaliada como?

PA2- A tutoria prestada durante o desenvolvimento da disciplina pode ser avaliada como?

PA3- 0 suporte técnico prestado durante 0 desenvolvimento da disciplina pode ser avaliado como?

PA4- A articulação e a adequação entre os momentos presenciais e à distância (conteúdos e carga-horária) da disciplina podem ser avaliadas como?

PA5- A prática didáticopedagógica desenvolvida pelo professor em momentos presenciais podem ser avaliadas como?

PA6- O nível de flexibilização da sua aprendizagem em relação ao tempo e ao espaço durante o desenvolvimento da disciplina pode ser avaliada como?

PA7- A avaliação da aprendizagem desenvolvida na disciplina pode ser avaliada como?

\begin{tabular}{cccccccccccc}
\multicolumn{2}{c}{ Ótima } & \multicolumn{2}{c}{ Boa } & \multicolumn{2}{c}{ Regular } & \multicolumn{2}{c}{ Ruim } & \multicolumn{2}{c}{ Péssima } & \multicolumn{2}{c}{ Total } \\
$\mathrm{f}$ & $\%$ & $\mathrm{f}$ & $\%$ & $\mathrm{f}$ & $\%$ & $\mathrm{f}$ & $\%$ & $\mathrm{f}$ & $\%$ & $\mathrm{f}$ & $\%$ \\
10 & 23,3 & 14 & 32,6 & 10 & 23,3 & 6 & 14,0 & 3 & 7,0 & 43 & 100
\end{tabular}

$\begin{array}{llllllllllll}7 & 16,3 & 19 & 44,2 & 12 & 27,9 & 3 & 7,0 & 2 & 4,7 & 43 & 100\end{array}$

$9 \begin{array}{llllllllllll}9 & 20,9 & 10 & 23,3 & 14 & 32,6 & 7 & 16,3 & 3 & 7,0 & 43 & 100\end{array}$

$\begin{array}{llllllllllll}7 & 16,3 & 14 & 32,6 & 9 & 20,9 & 6 & 14,0 & 7 & 16,3 & 43 & 100\end{array}$

$\begin{array}{llllllllllll}15 & 34,9 & 10 & 23,3 & 12 & 27,9 & 4 & 9,3 & 2 & 4,7 & 43 & 100\end{array}$

Observou-se que $32,6 \%$ dos alunos consideram boa a interação dialógica desenvolvida entre professor-tutor-aluno. Da mesma forma, outros estudos que avaliaram disciplinas semipresenciais e curso a distância na área da saúde, a reciprocidade e o respeito mútuo foram evidenciados. A comunicação no Ambiente Virtual de Aprendizagem (AVA) possibilitou aos estudantes o exercício do convívio e do respeito frente a diferentes pontos de vista, importante também para a aproximação do professor. ${ }^{11,15}$

Percebe-se a interação entre professor-tutor-aluno quando se permite identificar o nível de colaboração entre os sujeitos envolvidos na disciplina. Como em qualquer metodologia de aprendizagem, na EAD o aluno deve tomar atitude e sair da posição de passividade, quando passa a ser o processador de sua ciência. Entre discente e docente é imprescindível que haja reciprocidade, pois "não se ensina, aprende-se em reciprocidade de consciências".

A tutoria prestada durante as disciplinas foi avaliada como boa por $44,2 \%$ dos participantes e o suporte técnico prestado foi classificado como regular por $32,6 \%$ deles. 


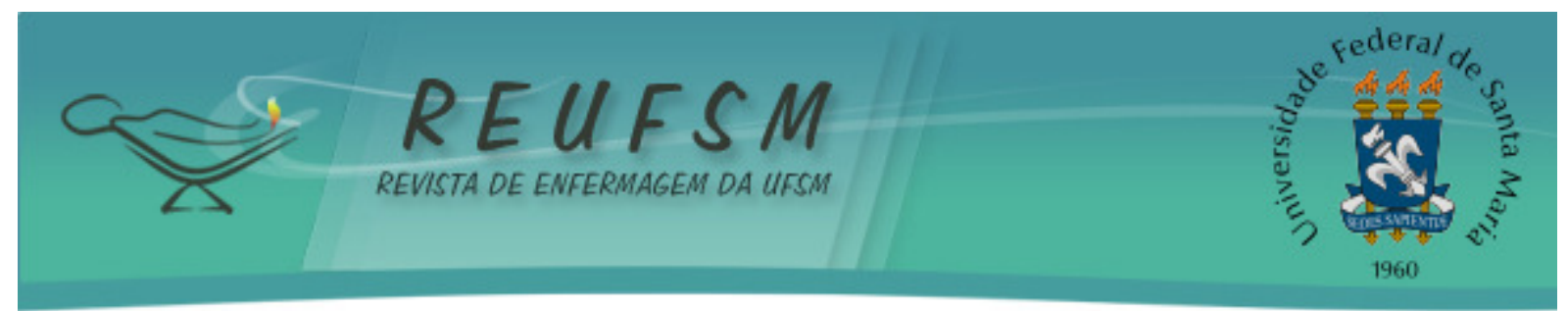

Como a efetividade da tutoria e do suporte aos alunos refere-se ao acompanhamento dos mesmos quanto às tarefas solicitadas e o contato sistemático ${ }^{13}$, neste estudo e em outro realizado sobre a avaliação do curso a distância sobre Hepatite $\mathrm{C}$, a participação em atividades como fóruns de discussões foi de $100 \%$. Isso pode ser explicado talvez pela estimulação por parte das tutoras com as questões norteadoras e o retorno dado pelas mesmas. Ainda, as tutoras transmitiam confiança aos alunos, dando-lhes a certeza de que não estavam sozinhos e transformaram o processo de ensino-aprendizagem em algo verdadeiramente compartilhado. ${ }^{14}$

O nível de flexibilização da sua aprendizagem em relação ao tempo e ao espaço e a avaliação da aprendizagem foram classificados como regulares pelos participantes, representados por $30,2 \%$ e $32,6 \%$ respectivamente. Esse não foi o mesmo resultado apresenta por outra pesquisa sobre vivência de estudantes de licenciatura em Enfermagem em disciplina na modalidade à distância, quando as alunas destacaram que o fato de poderem organizar o seu tempo e adequar as atividades às suas rotinas foi um dos fatores positivos do ensino a distância. ${ }^{16}$

Em relação à avaliação da disciplina, as alunas da mesma pesquisa também perceberam pontos positivos no estudo a distância, pois este exige mais esforço e dedicação em comparação as atividades de ensino presencial realizadas anteriormente. ${ }^{16}$

Nesse sentido, a avaliação deve ser vista como um processo de feedback que traga ao aprendiz informações oportunas no momento que ele precisa para desenvolver sua aprendizagem. Essas informações ao longo do processo de aprendizagem servem para corrigir erros e falhas e faz com que a avaliação seja um elemento incentivador e motivador da aprendizagem e não como uma forma de julgá-lo. ${ }^{3}$

A articulação/adequação entre os momentos presenciais e à distância foi avaliada como boa por $32,6 \%$ dos alunos. Já a prática didático-pedagógica desenvolvida pelo professor em momentos presenciais é considerada ótima por 34,9\% deles.

Opiniões semelhantes foram encontradas também em estudo que avaliou uma disciplina semipresencial de Bioquímica, pois destacou como questão chave da modalidade semipresencial, a integração e compatibilidade entre atividades presenciais e a distância. Se por um lado os alunos demonstram ter pouca autonomia para gerenciar as atividades presenciais e a distância, por outro, a implementação do AVA sem a necessária reorganização da disciplina como um todo, torna a participação dos mesmos limitada. ${ }^{11}$

Assim, os encontros ao vivo em cursos semipresenciais devem ser pontuadores de momentos marcantes. Ao vivo é mais fácil explicar e organizar o processo de aprendizagem, esclarecer, tirar dúvidas, organizar grupos, discutir propostas, motivar os alunos, atender às demandas específicas e fazer os ajustes necessários no programa. ${ }^{9}$

\section{Indicadores de resultados}

A tabela 3 apresenta dados relacionados aos indicadores de resultados que abordam as características relativas aos propósitos intermediários e últimos da educação. ${ }^{12}$ 


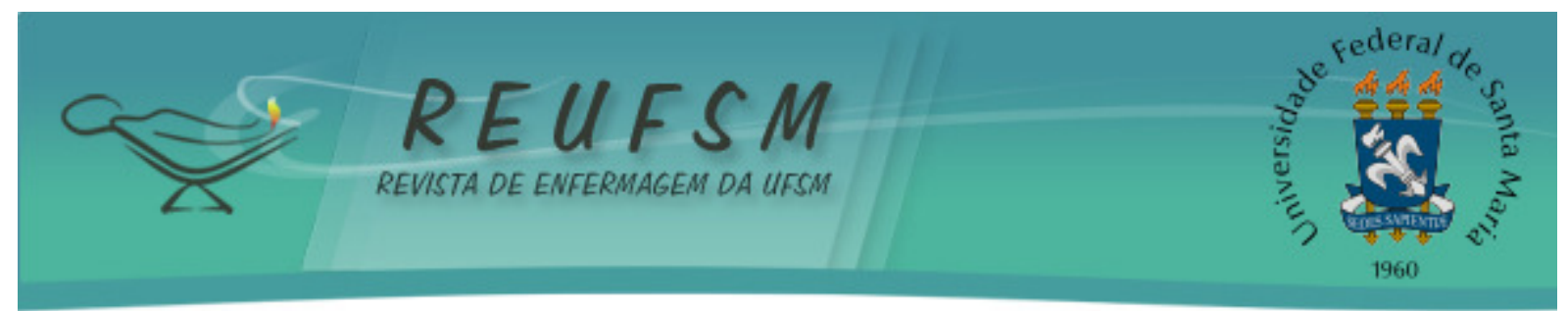

Tabela 3 - Porcentagem de respostas dos participantes da pesquisa, segundo indicadores de resultado. Presidente Prudente/SP, $2013(n=43)$.

Resultados

\begin{tabular}{cccccccccccc}
\multicolumn{2}{c}{ Ótima } & \multicolumn{2}{c}{ Boa } & \multicolumn{2}{c}{ Regular } & \multicolumn{2}{c}{ Ruim } & \multicolumn{2}{c}{ Péssima } & \multicolumn{2}{c}{ Total } \\
\hline $\mathrm{f}$ & $\%$ & $\mathrm{f}$ & $\%$ & $\mathrm{f}$ & $\%$ & $\mathrm{~F}$ & $\%$ & $\mathrm{f}$ & $\%$ & $\mathrm{f}$ & $\%$ \\
7 & 16,3 & 12 & 27,9 & 12 & 27,9 & 8 & 18,6 & 4 & 9,3 & 43 & 100
\end{tabular}

RA1 - A sua aprendizagem e o seu aproveitamento da disciplina podem ser avaliados como?

RA2- O desenvolvimento de suas

habilidades no uso de computador durante 0 transcorrer da disciplina pode $\begin{array}{llllllllllll}13 & 30,2 & 24 & 55,8 & 5 & 11,6 & 1 & 2,3 & 0 & 0,0 & 43 & 100\end{array}$ ser avaliado como?

RA3- O desenvolvimento da sua capacidade de autonomia e de auto-organização (tempo) durante 0 transcorrer da disciplina pode ser avaliado como?

A aprendizagem e o aproveitamento da disciplina foram avaliados como regular a boa por $27,9 \%$ dos entrevistados neste estudo e em outros estudos, observa-se que os alunos também destacaram esses pontos positivamente durante o curso a distância em disciplina semipresencial. Eles relataram que o conteúdo e a dinâmica contribuíram significativamente para seu aprendizado. ${ }^{6,11}$

Sobre o desenvolvimento das habilidades no uso de computador no transcorrer da disciplina, $55,8 \%$ dos discentes classificaram como bom ao contrário da pesquisa que avaliou a aplicação de ferramentas assíncronas no ensino da disciplina Didática. Os alunos desenvolveram pouca habilidade com fóruns, o que demonstra que as escolas de enfermagem precisam estimular a utilização de novas tecnologias desde a formação dos enfermeiros, a fim de promoverem a reflexão sobre suas possibilidades e limites. ${ }^{2}$

Quanto ao desenvolvimento da capacidade de autonomia e de auto-organização (tempo) $34,9 \%$ dos participantes consideraram bom, conforme outros estudos.

No estudo sobre a avaliação da disciplina semipresencial de Bioquímica, os autores consideraram o ambiente virtual como um auxiliador na gestão do tempo pelos alunos e no estudo sobre construção da autonomia entre estudantes de enfermagem em curso EAD, os alunos demonstraram o desenvolvimento da autonomia e destacaram a modalidade a distância como resgate à prática pedagógica ativa, muitas vezes precária no ensino presencial. ${ }^{11,15}$

\section{CONSIDERAÇÕES FINAIS}

Neste estudo foram avaliadas duas disciplinas em modalidade semipresencial pelos alunos de um curso de graduação em enfermagem, segundo os indicadores de entradas, processo e resultados. Os indicadores de entradas e resultados foram avaliados como bons, conforme a maioria das respostas. Já os indicadores de processo como suporte técnico prestado, nível de flexibilização da sua aprendizagem em relação ao tempo e ao espaço e a avaliação da aprendizagem desenvolvida na disciplina foram avaliados pelos alunos como regulares, o que demonstra a necessidade de reorganização e melhoria das disciplinas existentes.

Como limitação, destaca-se a impossibilidade de aplicação do instrumento a todos os sujeitos envolvidos na qualidade e no bom desempenho do processo de aprendizagem, ou seja, alunos, professores e pessoal de suporte. 0 instrumento foi aplicado somente aos alunos, uma vez que o próprio pesquisador é um dos professores e o pessoal de suporte não participou diretamente no processo de educação. Somado a isso, houve dificuldade de 


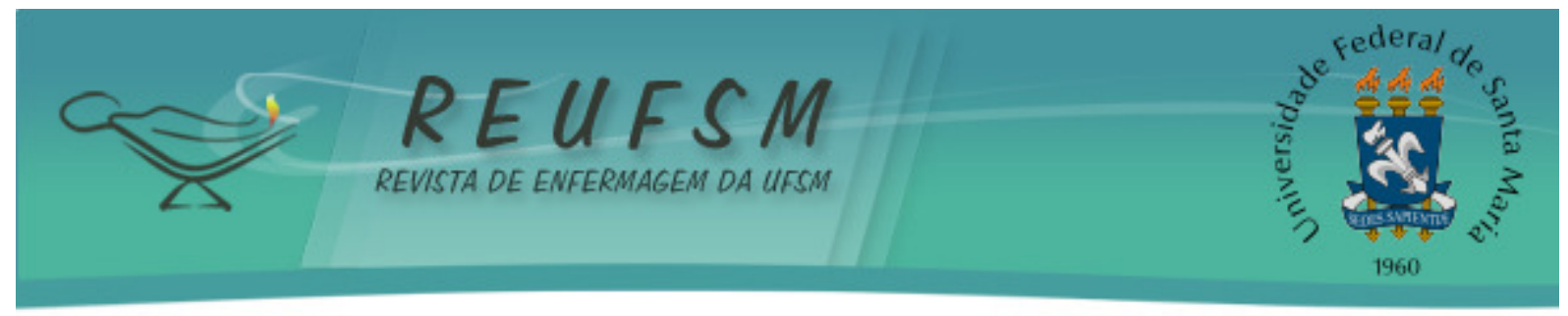

comparação dos resultados desse estudo com aqueles disponíveis na literatura devido ao pequeno número de pesquisas sobre essa temática no país.

A integração da modalidade semipresencial no curso de graduação em Enfermagem pode configurar mudanças no ensino, ultrapassar as possibilidades de estudo para além do espaço da sala de aula, criar oportunidades de interação professor-tutor-aluno e favorecer o posicionamento crítico e ativo do aluno frente ao mundo de informações disponíveis.

A Internet abre um horizonte inimaginável de opções para implementação do ensino a distância, que reorganiza e inova o processo de ensino-aprendizagem. As instituições de ensino precisam incentivar e capacitar os docentes para utilização das novas tecnologias, além de desenvolver novas pesquisas na área, pois se as TICs modificam a sociedade, podem transformar positivamente o ensino e a pesquisa.

\section{REFERÊNCIAS}

1. Martins TYC, Ribeiro RC, Prado C. Transdisciplinaridade na educação à distância: um novo paradigma no ensino de Enfermagem. Rev Bras Enferm [Internet]. 2011 jul/ago [acesso em 2013 dez 1];64(4):779-82.

Disponível

em:

http://www.scielo.br/scielo.php?script=sci_arttext\&pid=S0034-71672011000400023\&lng=en.

2. Peres HHC, Meira KC, Leite MMJ. Ensino de didática em enfermagem mediado pelo computador: avaliação discente. Rev Esc Enferm USP [Internet]. 2007 jun [acesso em 2013 dez 1];41(2):271-8. Disponível em: http: / /www.scielo.br/scielo.php?script=sci_arttext\&pid=S0080-

$62342007000200014 \&$ ing $=$ en.

3. Moran JM, Masetto MT, Behrens MA. Novas tecnologias e mediação pedagógica. Campinas: Papirus; 2000.

4. Merhy EE, Feuerwerker LCM. Novo olhar sobre as tecnologias de saúde: uma necessidade contemporânea. In: Mandarino ACS, Gomberg E, organizadores. Leituras de novas tecnologias e saúde. Salvador : EDUFBA; 2009. p. 29-74.

5. Bergold LB, Alvim NAT. A música terapêutica como uma tecnologia aplicada ao cuidado e ao ensino de enfermagem. Esc Anna Nery [Internet]. 2009 jul/set [acesso em 2014 maio 24];13(3):53742. Disponível em: http://www.scielo.br/scielo.php?script=sci_arttext\&pid=S1414$81452009000300012 \&$ lng $=$ en.

6. Sanches LMP, Lopes MHBM. Educação a distância sobre cardioversão e desfibrilação para enfermeiros. Rev Bras Enferm [Internet]. 2008 out [acesso em 2013 dez 1];61(5):583-8. Disponível em: http://www.scielo.br/scielo.php?script=sci_arttext\&pid=S0034$71672008000500009 \& \operatorname{lng}=e n$.

7. Vendruscolo C, Trindade LL, Prado ML, Luz JH, Dal Sasso GTM, Erdmann AL. A informática na formação e qualificação dos profissionais de saúde: uma revisão integrativa. Rev Enferm UFSM [Internet]. 2013 set/dez [acesso em 2014 jan 18];3(3):539-46. Disponível em: http://cascavel.ufsm.br/revistas/ojs-2.2.2/index.php/reufsm/article/view/7465.

8. Cogo ALP, Pedro ENR, Silva APSS, Schatkoski AM, Catalan VM, Alves RHK. Objetos educacionais digitais em enfermagem: avaliação por docentes de um curso de graduação. Rev Esc Enferm USP [Internet]. 2009 jun [acesso em 2013 set 23];43(2):295-9. Disponível em: http: / / www.scielo.br/scielo.php?script=sci_arttext\&pid=S008062342009000200006\&lng=en. doi:10.1590/S0080-62342009000200006. 


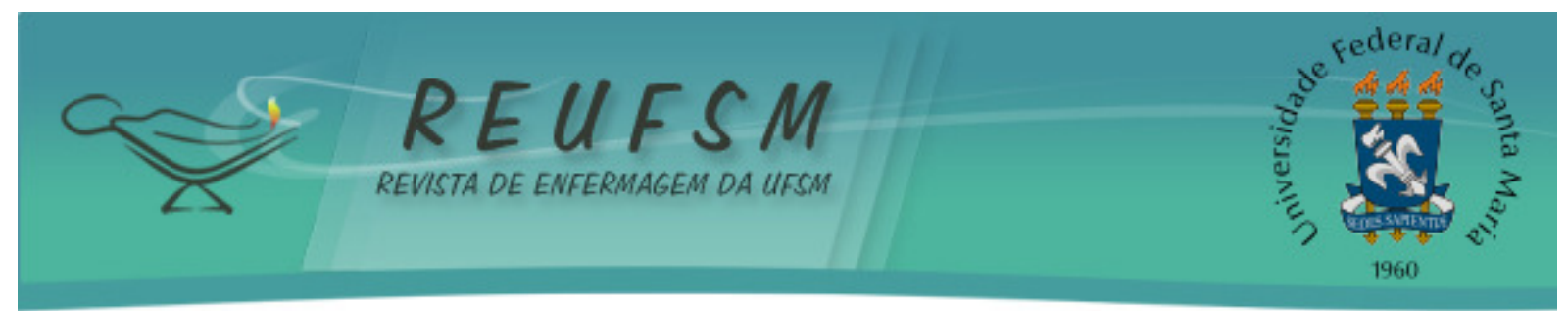

9. Moran JM. Os novos espaços de atuação do professor com as tecnologias. Rev Diálogo Educ. 2004;4(12):13-21.

10. Camacho ACLF. Análise das publicações nacionais sobre educação à distância na enfermagem. Rev Bras Enferm [Internet]. 2009 jul/ago [acesso em 2013 dez 1];62(4):58893. Disponível em: http://www.scielo.br/scielo.php?script=sci_arttext\&pid=S0034$71672009000400016 \&$ \&ng=en. doi:10.1590/S0034-71672009000400016.

11. Wardenski RF, Struchiner M, Espíndola MB, Giannella TR. Implementação da modalidade semipresencial em uma disciplina de bioquímica: análise das percepções de alunos do curso de medicina. In: VIII ENPEC Encontro Nacional de Pesquisa em Educação em Ciências. I CIEC Congreso Iberoamericano de Investigación em Ensenãnza de las Ciências; 2011 dez 5-9; Campinas. Campinas: Abrapec - SP; 2011. p. 1-13.

12. Bertolin JCG, De Marchi ACB. Instrumentos para avaliar disciplinas da modalidade semipresencial: uma proposta baseada em sistemas de indicadores. Avaliação (Campinas; Sorocoba) [Internet]. 2010 [acesso em 2013 dez 1];15(3):131-46. Disponível em: http: / / www.scielo.br/scielo.php?script=sci_arttext\&pid=S1414-

$40772010000300007 \&$ lng=pt\&tlng=pt. doi: 10.1590/S1414-40772010000300007.

13. Bertolin JCG, De Marchi ACB. Uma proposta de indicadores para avaliar a qualidade de disciplinas semipresenciais em cursos de graduação. RBCA. 2009;1(1):30-41.

14. Aparecida Jacomini R, Piai TH, Figueiredo RM. Avaliação de um curso de educação á distância sobre hepatite C. Invest Educ Enferm [Internet]. 2008 set [acesso em 2013 dez 1];26(2 Supl):98-104. Disponível em: http: / / www.scielo.org.co/scielo.php?script=sci_arttext\&pid=S0120$53072008000300008 \& \operatorname{lng}=e n$.

15. Cogo ALP. Construção da autonomia entre estudantes de enfermagem em curso EAD. In: $16^{\circ}$ Congresso Internacional de Educação a Distância; 2010 ago 31-set 3; Foz do Iguaçu. Foz do Igauçu: ABED - PR; 2010. p. 1-10.

16. Alves RHK, Cogo ALP. Vivência de estudantes de licenciatura em enfermagem em disciplina na modalidade à distância. Rev Gaúch Enferm. 2008;29(4):626-32.

Data de recebimento: $12 / 02 / 2014$

Data de aceite: 04/06/2014

Contato com autor responsável: Simone Shirasaki Orosco

Endereço postal: Avenida Salim Farah Maluf, 2500. CEP: 19026-240 Presidente Prudente/SP

E-mail: simone.orosco@hotmail.com 